\title{
MUSCLE INSULIN-LIKE GROWTH FACTOR-I MODULATES MURINE CRANIOFACIAL BONE GROWTH
}

\author{
H.J. Kok ${ }^{1}$, C.N. Crowder², L. Koo Min Chee ${ }^{2}$, H.Y. Choi², N. Lin² and E.R. Barton,2,* \\ ${ }^{1}$ Department of Applied Physiology and Kinesiology, College of Health and Human Performance, \\ University of Florida, Gainesville, FL, USA \\ ${ }^{2}$ Department of Anatomy and Cell Biology, School of Dental Medicine, University of Pennsylvania, \\ Philadelphia, PA, USA
}

\begin{abstract}
Insulin-like growth factor I (IGF-I) is essential for muscle and bone development and a primary mediator of growth hormone $(\mathrm{GH})$ actions. While studies have elucidated the importance of IGF-I specifically in muscle or bone development, few studies to date have evaluated the relationship between muscle and bone modulated by IGF-I in vivo, during post-natal growth. Mice with muscle-specific IGF-I overexpression $\left(m I g f 1^{+++}\right)$were utilised to determine IGF-I- and muscle-mass-dependent effects on craniofacial skeleton development during post-natal growth. $m I g f 1^{++}$mice displayed accelerated craniofacial bone growth when compared to wild-type animals. Virus-mediated expression of IGF-I targeting the masseter was performed to determine if post-natal modulation of IGF-I altered mandibular structures. Increased IGF-I in the masseter affected the mandibular base plane angle in a lateral manner, increasing the width of the mandible. At the cellular level, increased muscle IGF-I also accelerated cartilage thickness in the mandibular condyle. Importantly, mandibular length changes associated with increased IGF-I were not present in mice with genetic inhibition of muscle IGF-I receptor activity. These results demonstrated that muscle IGF-I could indirectly affect craniofacial growth through IGF-I-dependent increases in muscle hypertrophy. These findings have clinical implications when considering IGF-I as a therapeutic strategy for craniofacial disorders.
\end{abstract}

Keywords: Muscle-bone interaction, insulin-like growth factor I, craniofacial, bone development.

*Address for correspondence: Elisabeth R. Barton, PhD, Applied Physiology and Kinesiology, College of Health and Human Performance, University of Florida, 1864 Stadium Road, Gainesville, FL 32611, USA. Telephone number: +1 3522941714 Email: erbarton@ufl.edu

Copyright policy: This article is distributed in accordance with Creative Commons Attribution Licence (http://creativecommons.org/licenses/by-sa/4.0/).

\begin{tabular}{|c|c|c|c|}
\hline & List of Abbreviations & IGFD & $\begin{array}{l}\text { insulin-like growth factor-I } \\
\text { deficiency }\end{array}$ \\
\hline AAV & adeno-associated virus & IGF-I & insulin-like growth factor-I \\
\hline AB-PAS & alcian blue plus periodic acid-schiff & IGF-IR & IGF-I receptor \\
\hline AMIDE & a medical imaging data examiner & MCK & muscle creatine kinase \\
\hline ANOVA & analysis of variance & $m I g f 1$ & muscle-specific IGF-I transgenic \\
\hline CI & confidence interval & & overexpression mice \\
\hline DAPI & 4',6-diamidino-2-phenylindole & MLC & myosin light chain \\
\hline DICOM & $\begin{array}{l}\text { digital imaging and communications } \\
\text { in medicine }\end{array}$ & $\begin{array}{l}\text { PBS } \\
\text { PCA }\end{array}$ & $\begin{array}{l}\text { phosphate-buffered saline } \\
\text { principal component analysis }\end{array}$ \\
\hline ELISA & $\begin{array}{l}\text { enzyme-linked immunosorbent } \\
\text { assay }\end{array}$ & $\begin{array}{l}\text { PC1 } \\
\text { PC2 }\end{array}$ & $\begin{array}{l}\text { principal component } 1 \\
\text { principal component } 2\end{array}$ \\
\hline GAPDH & $\begin{array}{l}\text { glyceraldehyde 3-phosphate } \\
\text { dehydrogenase }\end{array}$ & $\begin{array}{l}\text { RIPA } \\
\text { SDS-PAGE }\end{array}$ & $\begin{array}{l}\text { radioimmunoprecipitation assay } \\
\text { sodium dodecyl sulphate- }\end{array}$ \\
\hline gc & genome copies & & polyacrylamide gel electrophoresis \\
\hline $\mathrm{GH}$ & growth hormone & SEM & standard error of the mean \\
\hline GHD & GH deficiency & WT & wild type \\
\hline Grp94 & glucose-regulated protein 94 & $\mu \mathrm{CT}$ & micro-computed tomography \\
\hline
\end{tabular}




\section{Introduction}

Craniofacial structures of children with GHD and severe IGFD appear abnormal due to delayed growth in isolated regions. In addition to the appearance of a childish face but with a large skull, they often require orthodontic treatment due to higher incidence of tooth crowding (Hwang and Cha, 2004; Wójcik and Beń-Skowronek, 2020). Indeed, disproportionate growth occurs in the jaw and cranial base structures of boys with short stature, with the addition of delayed tooth eruption (Kjellberg et al., 2000). Thus, $\mathrm{GH}$ replacement therapy combined with orthodontic treatment is a standard regimen for children with GHD (Barton and Crowder, 2010; Hwang and Cha, 2004; Wójcik and Beń-Skowronek, 2020).

A large proportion of GH-stimulated postnatal bone growth is mediated by IGF-I (Barton and Crowder, 2010; Litsas, 2015; Yakar et al., 2018). IGF-I plays a major role in skeletal muscle and bone development (Barton and Crowder, 2010; Bikle et al., 2015; Lupu et al., 2001; Powell-Braxton et al., 1993; Vassilakos et al., 2019). Mice with global ablation of IGF-I exhibit severe growth retardation in bones (Baker et al., 1993; Lupu et al., 2001) and muscles (Powell-Braxton et al., 1993), indicating the importance of this growth factor for these tissues and replicating the clinical hallmarks of humans with loss of function mutations in the GH/IGF-I axis (Batey et al., 2014; Dauber et al., 2014). The primary source of systemic IGF-I is the liver; however, local sources of IGF-I are sufficient for normal growth. For example, in the face of a $75 \%$ reduction in circulating IGF-I through liver-specific deletion of $I g f 1$, there are no apparent effects on postnatal body or muscle size (Sjögren et al., 1999; Yakar et al., 1999). Modulation of local muscle production of IGF-I in mice substantiate that muscle mass is dependent upon local IGF-I levels. For instance, muscle-specific transgenic overexpression of IGF-I from birth results in increased muscle mass and force generation in young adult mice (Musarò et al., 2001). In contrast, muscle-targeted deletion of Igf1 or its chaperone, Grp94 at birth causes a reduction in muscle mass and function in young mice (Barton et al., 2012; Vassilakos et al., 2019). Bone appears to be dependent upon endocrine and paracrine IGF-I (Tahimic et al., 2013). Liver-specific deletion of IGF-I, which significantly reduces endocrine IGF-I, causes defects in radial growth and bone mineral density of long bones even though linear bone growth appears normal (Yakar et al., 2009). Within the growth plate, IGF-I from chondrocytes is crucial for post-natal bone development (Govoni et al., 2007; Wang et al., 2011). However, it remains unclear if the neighbouring muscle can provide a local source of IGF-I for the bone.

Despite being a relatively small protein, IGF-I harbours complexity through alternative splicing and post-translational processing that modulates its potency and stability (reviewed by Vassilakos and Barton, 2018). There are multiple classes, or isoforms, that arise from use of either exon 1 (class 1 ) or 2 (class 2 ) at the $5^{\prime}$-end and from the exclusion (class A) or inclusion (class B/C) of exon 5 at the $3^{\prime}$ end of the gene. Exons 3 and 4 are invariant in all classes and encode the mature IGF-I protein. 3 '-end alternative splicing encodes distinct carboxy-terminal sequences, called E peptides, which have been shown to confer differential activity and localisation within cells (Barton et al., 2010; Durzynska et al., 2013b; Kandalla et al., 2011; Yang and Goldspink, 2002). Class A isoforms are predominantly expressed in homeostatic tissues. For skeletal muscle, the proform of IGF-IA, which retains the EA-peptide, as well as its N-glycosylated pro-IGF-IA constitute the largest proportion of IGF-I molecules stored in the tissue, and the EA peptide, regardless of its glycosylation, appears to enhance storage of IGF-I in the extracellular matrix (Durzynska et al., 2013a; Hede et al., 2012). Similarly, N-glycosylated pro-IGF-IA is also secreted by articular chondrocytes and binds tightly to heparin (Shi et al., 2018). Further, potency of IGF-IR activation is dependent upon the form of IGF-I, with relative activity of pro-IGF-I $\geq$ mature IGF-I > glycosylated pro-IGF (Durzynska et al., 2013a).

As muscle mass and strength changes, this alters bone properties. Several mouse models have been used to demonstrate the mechanical influence of muscle on bone. For example, mice expressing a dominant negative IGF-IR in skeletal muscle have smaller muscle size (Fernández et al., 2002) and a slenderer long-bone phenotype due to increased osteoclast activity (Kawashima et al., 2009). This also extends to the craniofacial region, where muscle weakness can lead to many complications (Conith et al., 2019). For instance, unilateral Botox-induced paralysis of masseter muscle leads to decreased ramus height and bigonial widths (Seok et al., 2018), along with mandible and zygomatic arch volumes on the paralysed side (Balanta-Melo et al., 2018; Matic et al., 2007). Further, patients suffering from Duchenne muscular dystrophy develop severe open bite malocclusions due to diminished muscle force generating capacity transmitted to the skeleton as the condition progresses (Morel-Verdebout et al., 2007). While it is generally accepted that muscle activity provides a mechanical stimulus for bone growth, local growth factors secreted by muscle, including myostatin and IGF-I, may also alter bone growth (Barton and Crowder, 2010; Bikle et al., 2015; Brotto and Bonewald, 2015; Hamrick et al., 2010; Hamrick, 2011; Herrmann et al., 2020; Lee et al., 2020). There is an interaction between mechanical loading and local IGF-I levels in load-mediated bone anabolism (Klein-Nulend et al., 2013; Lean et al., 1995; Reijnders et al., 2007). For instance, osteoblast-specific IGF-I overexpression displays increases in periosteal bone formation post-mechanical loading (Gross et al., 2002). In contrast, osteoblast-specific IGF-I deletion does not alter the ratio of bone volume to tissue volume, trabecular bone mineral density and thickness after a bout of axial loading, thus losing the anabolic cues 
from mechanical loading (Kesavan et al., 2011). In the craniofacial region, IGF-I has been shown to induce chondrocyte proliferation in vitro (Fuentes et al., 2002) and endochondral bone formation (Suzuki et al., 2004) in the mandibular condylar cartilage region following injection of recombinant IGF-I into the articular cartilage. Similarly, IGF-I secreted from blood vessels is a critical source to drive jaw growth during development (Marchant et al., 2020). Nevertheless, a specific role of IGF-I from skeletal muscle in the craniofacial region has yet to be established.

The goal of the present study was to determine if IGF-I production by craniofacial muscle could modulate craniofacial bone growth. The study utilised well-established transgenic mouse models of muscle-specific overexpression of the most abundant IGF-I isoform, Igfla (Musarò et al., 2001), or musclespecific inhibition of IGF-IR activity (Fernández et al., 2001), coupled with post-natal virus-mediated delivery of Igfla into the masticatory muscle. Cephalometric analysis was performed to identify regions of craniofacial growth modulated by muscle IGF-I.

\section{Materials and Methods}

\section{Animals}

All animal experiments were approved by the University of Pennsylvania Institutional Animal Care and Use Committee. Mice were housed in an animal facility under a $12 \mathrm{~h}$ light/dark cycle and ad libitum access to food and water. C57BL/6 (WT) mice and $M L C / m I G F-I\left(m I g f 1^{++}\right)$mice, which expresses rat Igf1 $a$ under the MLC1/3 promoter/enhancer (Musarò et al., 2001), were used. Igf1a encodes the class I signal peptide, mature IGF-I and the EA-peptide of the predominant IGF-I isoform. $N=4-6$ mice/strain/ timepoint were sacrificed at postnatal weeks 3, 6, 9 and 12. Additionally, 2-week-old MKR mice, which harbour a dominant negative IGF-IR transgene under the MCK promoter (Fernández et al., 2001) were used to prevent IGF-I activity in muscle. MKR mice were backcrossed onto the C57BL/6 strain for 10 generations, as described previously (Barton et al., 2010).

\section{Muscle viral injections}

2-week-old mice were lightly anaesthetised with intraperitoneal injection of $10 \mathrm{mg} / \mathrm{kg}$ ketamine and $80 \mathrm{mg} / \mathrm{kg}$ xylazine and subjected to a single intramuscular injection, termed a local injection, of recombinant AAV serotype $2 / 8$ harbouring the cDNA for mouse Igf1a, regulated by the MLC1/3 promoter/ enhancer, as described previously (Barton, 2006). This is the murine equivalent to the isoform expressed in $m I g f 1^{+/+}$mice (+ IGF). The left masseters were injected with $50 \mu \mathrm{L}$ of $1 \times 10^{11} \mathrm{gc} / \mathrm{mL}$ AAV diluted in PBS (AAV-IGF-I), while the right masseter received an equal amount of PBS. WT mice $(n=4$ males and $n=3$ females) were used to measure the mandibular base plane angle, along with additional $(n=5)$ mice as non-injected control. These mice were sacrificed 1 month later and masseter muscles were snap-frozen to measure IGF-I content. Similar procedures were performed when comparing MKR and WT mice, with measurements obtained 1 month post-injection ( $n=4$ /genotype).

\section{$\mu \mathrm{CT}$ analysis}

Mice were anaesthetised with an intraperitoneal injection of $10 \mathrm{mg} / \mathrm{kg}$ ketamine and $80 \mathrm{mg} / \mathrm{kg}$ xylazine prior to placement into a $\mu \mathrm{CT}$ scanner (MicroCAT II -ImTeK/Siemens) at the University of Pennsylvania Small Animal Imaging Facility. All samples were scanned using the same integration time of $11 \mathrm{~min}$ and $28 \mathrm{~s}$ with high resolution and each slice was taken at increments of $100 \mu \mathrm{m}$ to standardise the measurement. 3D image reconstruction was done to $100 \mu \mathrm{m}$ at an optimised grayscale using Image Reconstruction, Visualisation and Analysis V3.7 (ImTeK/Siemens). Mice were euthanised by $\mathrm{CO}_{2}$ asphyxiation at the end of the measurements and skulls and masticatory muscles were removed for additional processing. Then, all images were saved and exported in DICOM format. Cephalometric analysis of the skull was performed using $\mu \mathrm{CT}$ AMIDE software (Loening and Gambhir, 2003). Craniofacial dimensions were measured in $3 \mathrm{D}$ at $80 \mathrm{kVp} / 500 \mu \mathrm{A}$, with a resolution of $20 \mu \mathrm{m}$ isotropic, for accurate landmark identification. All landmarks were identified on a transverse 2D image rendered from the $\mu \mathrm{CT}$ scanner and the distance between fiducial markers oriented in $\mathrm{X}, \mathrm{Y}$ and $\mathrm{Z}$ coordinates was determined mathematically [length = square root of $(\Delta X+\Delta Y+\Delta Z)]$, adapted from previously established craniofacial landmarks (Omar RamirezYañez et al., 2005; Singleton et al., 2006; Vandeberg et al., 2004) (Fig. 1, Table 1). Left and right landmarks were identified for those in the mid-sagittal plane.

To ensure intra-examiner reliability and precision, 1 animal at random from each timepoint (e. g. 3, 6, 9 and 12 weeks) was re-measured two additional times post- $\mu \mathrm{CT}$ and at least $7 \mathrm{~d}$ apart using AMIDE. Then, those 3 measurements were compared to the averages within the subject. SEM was used to detect the method error of how far the additional measurements were likely to deviate from the average of that particular subject. SEM ranged from $0.02(0.04 \%)$ to $0.11(0.37 \%)$ for linear measurements and from 0.21 $(0.37 \%)$ to $1.93(2.90 \%)$ in angular measurements (Table 2), indicating that linear measurements had less noise in the data than angular measurements.

\section{Muscle IGF-I protein content}

IGF-I levels were measured using a commercially available ELISA kit specific for rodent IGF-I (MG100, R\&D Systems), as described previously (Pfeffer et al., 2009), following the manufacturer's protocol. Small portions of frozen masseters were weighed, homogenised in PBS and subjected to a freeze-thaw cycle. Samples were centrifuged at 5,000 $\times g$ for $5 \mathrm{~min}$ 
and the supernatants were used for measurements of total IGF-I. A standard curve was generated based on the recombinant mouse IGF-I provided by the kit to calculate IGF-I content in the muscles. There was no cross-reactivity with IGF-I binding proteins or IGF-II, since this kit specifically detects total rodent IGF-I.

Immunoblotting for IGF-I was also performed to enable evaluation of the forms of IGF-I produced in the masseter by transgenic or viral expression, as previously described (Durzynska et al., 2013a). Briefly, snap-frozen muscles were homogenised in RIPA buffer (9806, Cell Signaling Technology) supplemented with protease (1: 100, P8340, Millipore) and phosphatase (1:100, P5726, Millipore) inhibitors. Tissue homogenates were centrifuged to pellet debris and total protein was measured in the supernatant using the BCA Protein assay kit (23225, Thermo Fisher Scientific), following the manufacturer's protocol.

Equal amounts of protein from tissue lysates were subjected to SDS-PAGE and transferred to polyvinylidene fluoride membranes (Immobilon-P; Millipore). Recombinant murine IGF-I (R\&D Systems) was loaded onto each blot (1-2 ng per lane) as a positive control for mature IGF-I. The following primary antibodies were used: IGF-I (1 : 500, AF791, R\&D Systems) and GAPDH (1 : 5,000, SC-32233, Santa Cruz). After washing, membranes were incubated with appropriate secondary antibodies (Li-Cor Biosciences). The specific bands on the membranes were visualised using the LI-COR, ODYSSEY CLx System (Li-Cor Biosciences). Analysis was performed
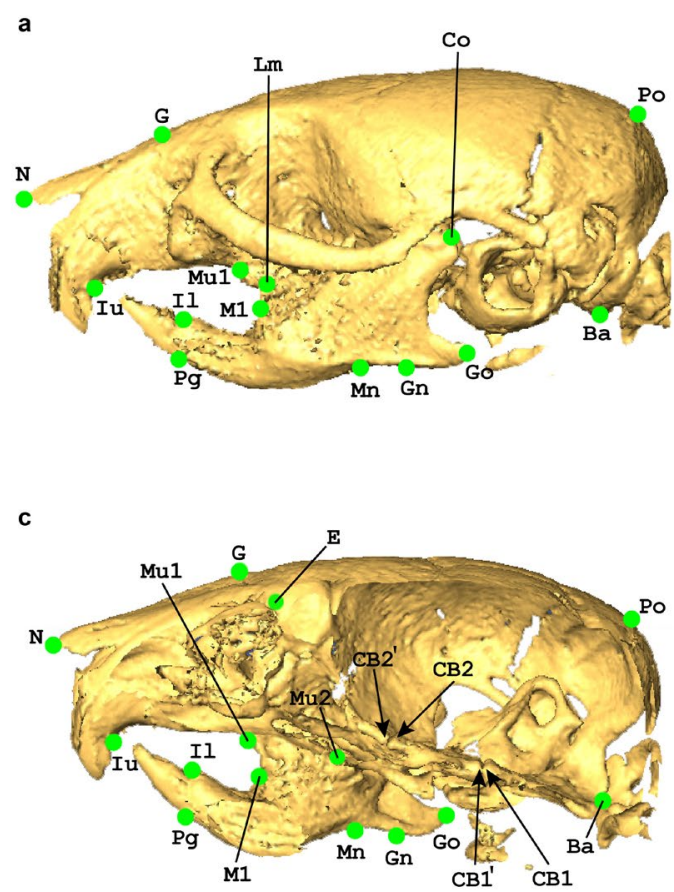

using Image Studio, version 5.2 software (Li-Cor Biosciences).

\section{Histological analysis of mandibular condyles}

Mid-sagittal sections of mandibular condyles from $m I g f 1^{+/+}$and WT mice at 3, 6, 9 and 12 weeks of development were dewaxed in xylene and rehydrated with graded EtOH. Slides were stained with haematoxylin and eosin or AB-PAS. Slides were immersed in Citrisolv (Fisher Scientific) and mounted using Cytoseal 60 (Fisher Scientific). Alcian blue stains the chondrocyte layer blue, which was measured by brightfield microscopy.

For cyclin D3 immunofluorescent staining, dewaxed and rehydrated samples underwent antigen retrieval using sodium citrate buffer $(10 \mathrm{mmol} / \mathrm{L}$, $\mathrm{pH}$ 6.0) and blocked for $1 \mathrm{~h}$ at room temperature with $5 \%$ bovine serum albumin (BP9703-100, Fisher Scientific). Sections underwent overnight incubation with primary antibody for cyclin D3 (1 : 500, antimouse, 2936, Cell Signalling Technology) at $4{ }^{\circ} \mathrm{C}$. After washing with PBS, sections were incubated with secondary antibody (1 : 2,000, 488 anti-mouse IgG A28175, Invitrogen) for $1 \mathrm{~h}$ at room temperature. Slides were mounted using Vectashield containing DAPI (Vector Laboratories). Fluorescence microscopy (Leica DMR) of sections was performed to observe the green cyclin D3 positive cells and nuclei. Signal intensity was optically filtered to identify the cyclin D3 positive region indicative of the proliferating zone (OpenLab, Improvision). 3 separate measurements were taken from each section $(n=2-4$ mice/genotype/
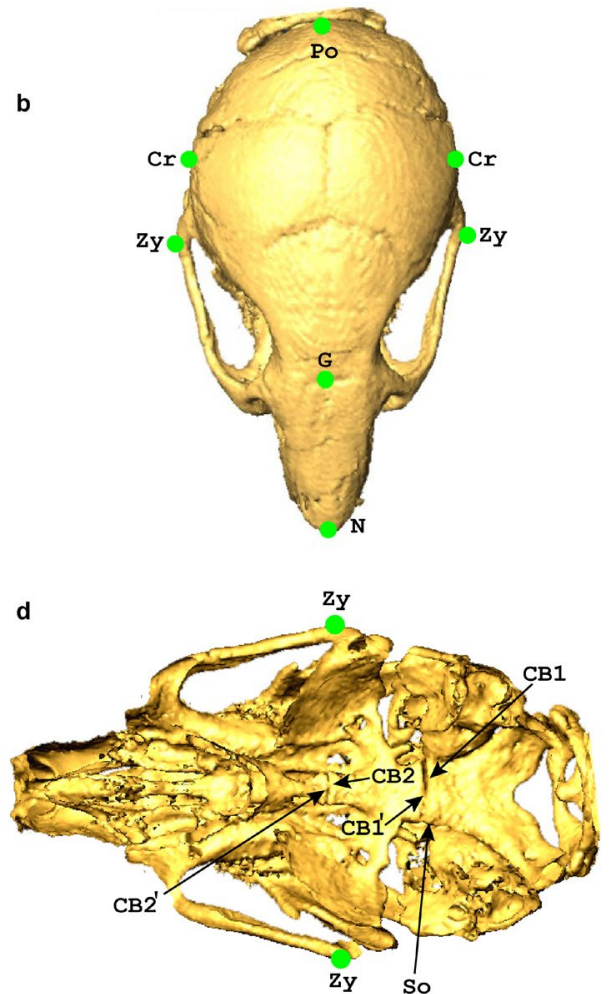

Fig. 1. Cephalometric landmarks used in $\mu \mathrm{CT}$ analysis. Schematic views of the mouse cranium from (a) lateral view and (b) superior view to identify cranial vault and mandibular landmarks. (c) Deep sagittal and (d) superior view of the cranial base landmarks were used to visualise cranial base landmarks. Right and left landmarks of the midsagittal plane were identified and recorded. 
Table 1. List of cephalometric landmarks followed by their definitions. Adapted from Omar RamirezSingleton et al., 2006; Vandeberg et al., 2004; Yañez et al., 2005.

\begin{tabular}{|c|c|}
\hline Landmarks & Description \\
\hline Co & Most posterior and superior point on the mandibular condyle \\
\hline Go & Most posterior point on the mandibular ramus \\
\hline Mn & Junction of mandibular ramus and corpus \\
\hline Gn & Most inferior point on ramus that lies on perpendicular bisector of line Go-Mn \\
\hline Il & Most anterior-superior point on mandibular corpus superior to mandibular incisors \\
\hline So & Intersection of most anterior tympanic bulla and superior border of sphenoid bone \\
\hline Iu & Most anterior-inferior point on maxilla posterior to maxillary incisors \\
\hline Pg & Most anterior-inferior point on the lower border of the mandible \\
\hline M1 & Junction of alveolar bone and mesial surface of mandibular first molar \\
\hline Mu1 & Junction of alveolar bone and mesial surface of maxillary first molar \\
\hline Mu2 & Junction of alveolar bone and distal surface of maxillary third molar \\
\hline PM & Bisecting line between Pg right and Pg left \\
\hline \multicolumn{2}{|c|}{ Cranial vault landmarks } \\
\hline N & Most anterior point on the nasal bone \\
\hline E & Most inferior point of frontal bone at location of frontal sinus \\
\hline G & Junction of the nasal bone and cranium \\
\hline Po & Most posterior and superior point on skull \\
\hline Ba & Most lateral points on the zygomatic arch \\
\hline Zy & Most lateral points of the cranial vault \\
\hline Cr & Cranial base landmarks \\
\hline \multicolumn{2}{|c|}{} \\
\hline CB1 & Most anterior point on occipital bone at spheno-occipital synchondrosis \\
\hline CB1' & Most posterior point on sphenoid bone at spheno-occipital synchondrosis \\
\hline CB2 & Most anterior point on sphenoid bone at spheno-basispheno synchondrosis \\
\hline CB2' & Most posterior point on basisphenoid bone at spheno-basispheno synchondrosis \\
\hline \multicolumn{2}{|c|}{} \\
\hline
\end{tabular}

timepoint), for chondrocyte layers through AB-PAS staining and for proliferating zone through cyclin D3 staining.

\section{Statistical analysis}

Statistical analysis was performed using GraphPad Prism 8 (GraphPad Software, Inc.). Two-tailed unpaired student's $t$-test was used to compare WT and IGF-I transgenic models, as well as injected $v$. non-injected masseters. Two-way ANOVA was used to test within group difference across developmental time points followed by Tukey's and Bonferroni's post-hoc analysis. Pearson's correlation coefficient was performed to determine relative growth and the slope was determined by linear regression. In addition, $\mathrm{R}$ packages ggbiplot (Web ref. 1) and factoextra (Web ref. 2) were used to perform PCA.

\section{Results}

Transgenic muscle-specific Igf1 overexpression accelerated whole body growth and long bone development

Transgenic overexpression of muscle IGF-I is beneficial for skeletal muscle mass and function without changing circulating IGF-I (Barton and Crowder, 2010; Musarò et al., 2001; Paul and
Rosenthal, 2002); however, it is unknown if it influences the neighbouring bone. Mice 3, 6, 9 and 12 weeks old were analysed to capture growth rates from pre-pubertal to young adult stages (Fig. 2a). Total body weight of mice 6 to 12 weeks old in both strains was significantly larger than 3 weeks old, passing the pre-pubertal stage and entering into the adolescent stage (Fig. 2b). WT mice grew continuously with age, as indicated by significantly larger body weight at 12 weeks old when compared to 6 and 9 weeks old. In contrast, the body weight of $m I g f 1^{+++}$mice displayed the most dramatic increase between 3 and 6 weeks of age, after which a plateau was maintained. Importantly, $m I g f 1^{+/+}$mice were significantly heavier than WT mice, from the 6- to 9-week timepoint, but not different at the 3- or 12week timepoint. Humerus length was measured to determine long bone development on the forequarter region of mice. $m I g \mathrm{II}^{+++}$mice had significantly longer humeri than WT mice 6-12 weeks old (Fig. 2c). Similar to body weight, the humeri in WT and $m I g f 1^{+/+}$mice 6-12 weeks old were significantly longer than at 3 weeks of age. The humeri of WT animals reached their maximum length by 9 weeks old, indicated by a significant difference comparing the 9- and 12 -week to the 6-week timepoint. In contrast, the humeri of $\mathrm{mIgf1}^{+++}$mice exhibited continued growth at the 12-week timepoint, indicated by a significant 
difference between the 12- and 6-week timepoints. Comparisons of humerus length and body weight of WT and $m I g f 1^{+/+}$mice showed high correlation coefficients of relative growth in both strains (Fig. 2d). The $17 \%$ difference in slope between genotypes was not significant.

\section{Craniofacial bone development is modulated by muscle-specific IGF-I}

To determine if IGF-I from craniofacial muscles contributed to craniofacial bone development, $\mu \mathrm{CT}$ imaging was utilised to perform cephalometric measurements of skulls from WT and $m \operatorname{Ig} f 1^{+/+}$mice. PCA was applied to the data set to characterise the variation in cephalometric measurements. PCA revealed that PC1 dominated all dimensions, with $63.8 \%$ explained variances (Fig. 3a). Graphs of PC1 and PC2, showed that the craniofacial dimension of the 3-week timepoint for both genotypes were different from the 6-, 9- and 12-week timepoints (Fig. 3b). Further, craniofacial dimensions of $m I g f 1^{+/+}$ mice had smaller ellipse sizes $(95 \% \mathrm{CI})$ at the 3and 6-week timepoints but larger at the 12-week timepoint, indicating that changes in variability occurred as age progressed. Total skull length was

a

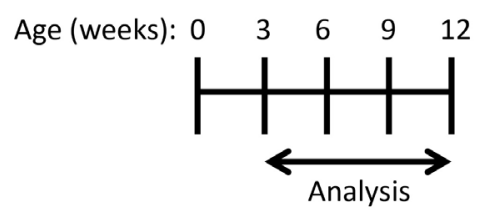

c

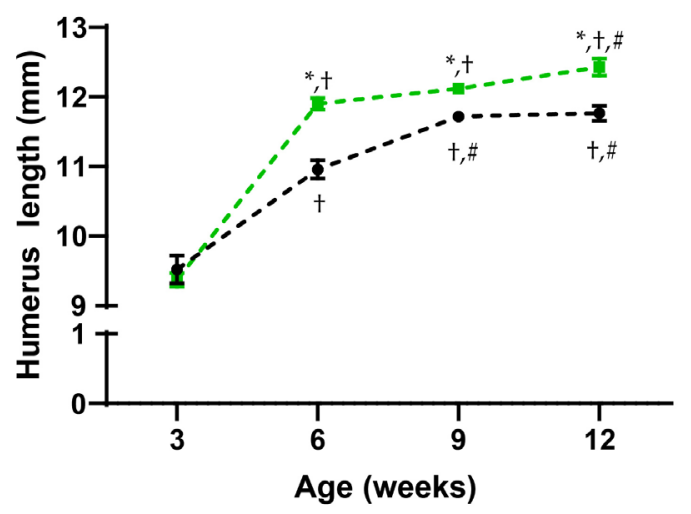

measured in WT and $m I g f 1^{+/+}$mice (Fig. 3c). $m I g f 1^{+/+}$ mice had longer skull length when compared to WT mice at the 9-week timepoint (Fig. 3d). Skull lengths at 3 weeks of age were significantly shorter than at the 6-, 9- and 12-week timepoints in both genotypes, supporting the PCA findings.

Further analysis within the cranial vault was performed to identify areas that contributed to the increased skull length in $m I g f 1^{+/+}$mice. $m I g f 1^{+/+}$mice had longer transverse zygomatic widths at 6 and 9 weeks of age when compared to WT animals (Table 2). Similar to total skull length, 3 weeks old mice had shorter zygomatic widths when compared to the 6-, 9- and 12-week timepoints in both genotypes. $\mathrm{mIgf1}^{+/+}$ mice retained similar zygomatic widths from 6 to 12 weeks of age, yet WT mice were still growing and were able to catch up at 12 weeks of age, indicated by a significant difference comparing the 6- and 12-week timepoints and no difference between strains. $m I g f 1^{+/+}$ mice also had longer anterior cranial base lengths at 6 weeks of age and sphenoid bone lengths at the 12-week timepoint when compared to WT mice. The growth of sphenoid bone length in $m I g f 1^{+/+}$mice was evident from comparisons of the 3-week timepoint with the 9- and 12-week timepoints. Besides a main

b

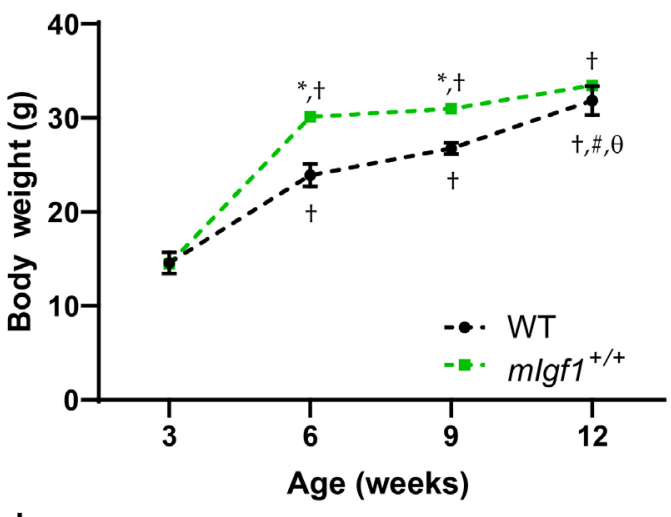

d

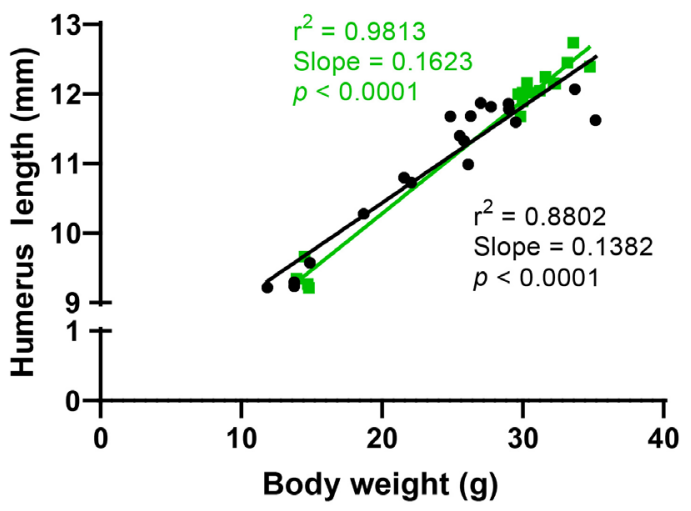

Fig. 2. Overexpression of muscle IGF-I accelerated long-bone development. (a) Scheme showing experimental timepoints for male mice $\left(n=4-6 /\right.$ genotype/timepoint). (b) $m I g f 1^{+/+}$mice were significantly larger in body mass when compared to WT mice at 6 and 9 weeks of age but not different by 12 weeks of age. (c) $m I g f 1^{+++}$mice had significantly longer humerus starting at 6 weeks of age when compared to WT mice. (d) Both $m I g f 1^{+++}$(17 pairs, $95 \%$ CI: 0.97 to 1) and WT (19 pairs, $95 \%$ CI: 0.84 to 0.98) mice showed positive linear relationships between humerus length and body weight; however, there was no significant difference between the slopes of each genotype. (b,c) Data presented are mean \pm SEM. ${ }^{*} p<0.05$ between genotypes. $p<0.05:{ }^{+}$vs. 3 weeks, ${ }^{\#}$ vs. 6 weeks and ${ }^{\theta}$ vs. 9 weeks within group (Tukey's post-hoc analysis). 

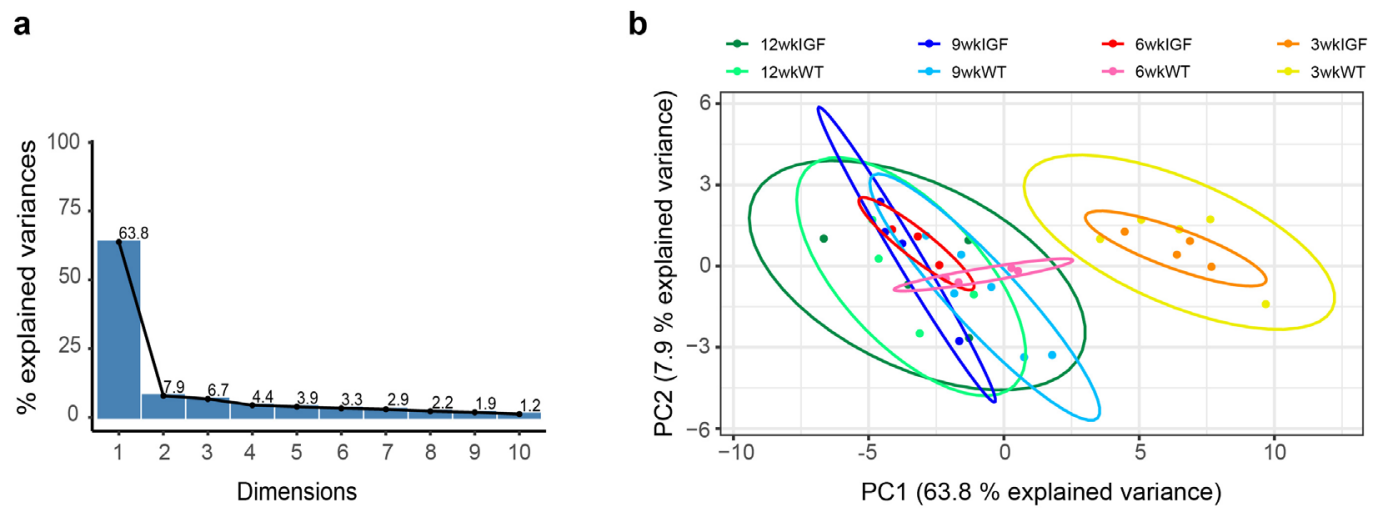

C
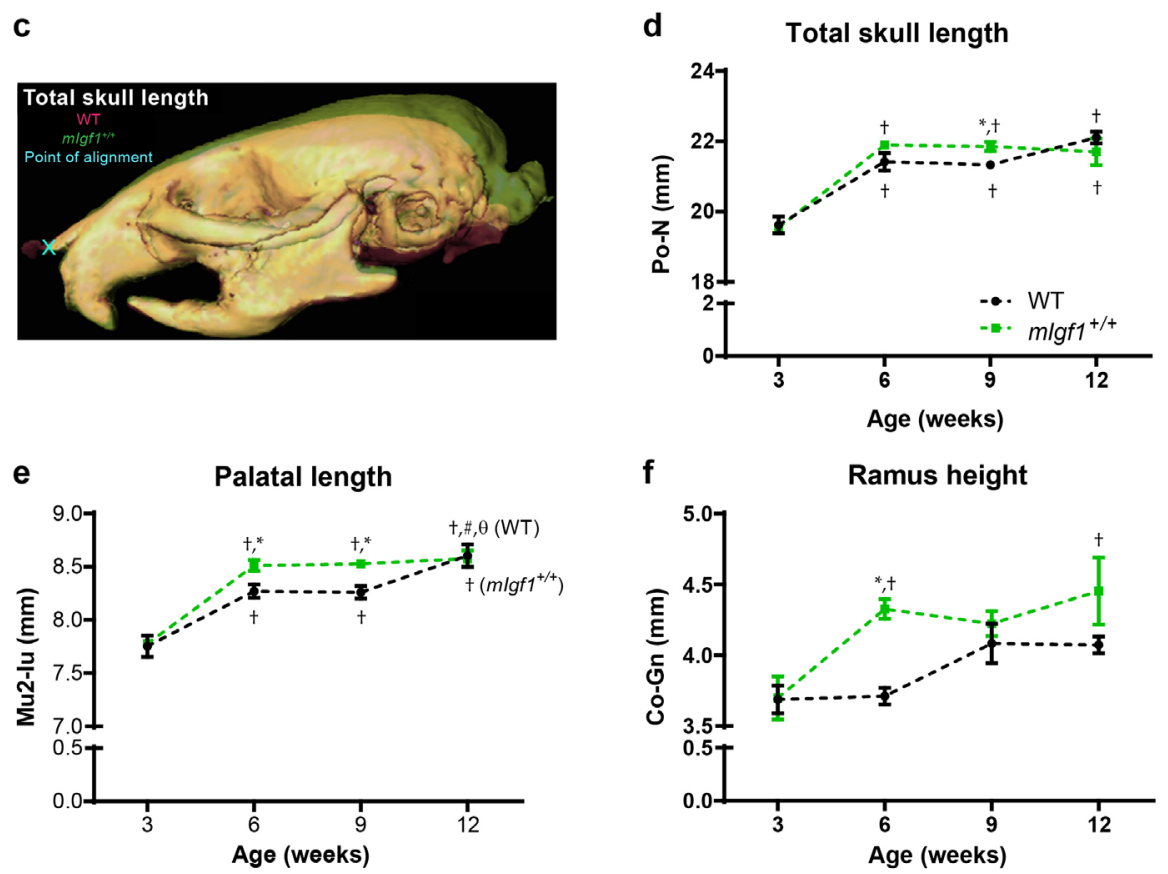

$\mathbf{g}$

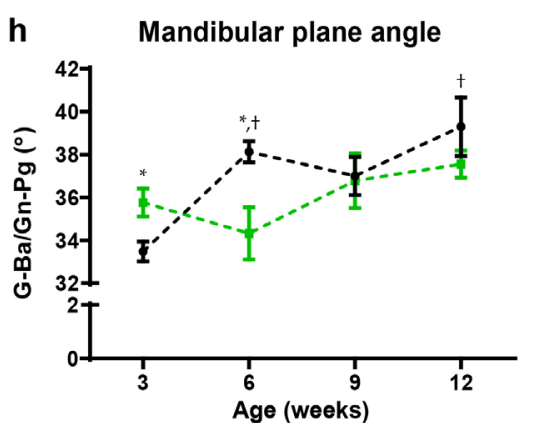

Fig. 3. Overexpression of muscle IGF-I expedited craniofacial bone development. (a) Scree plot from PCA of cephalometric measurements showing the domination of the first dimension (PC1) with the highest eigenvalues. (b) PCA plot indicates that the 3-week timepoints for both genotypes were different from 6, 9 and 12 weeks of age with varying ellipse sizes (95\% CI). (c) 2D $\mu$ CT images superimposed to show the difference in total skull length between a representative WT and $m I g f 1^{+/+}$mice at 9 weeks of age. (d) A representative neurocranium measurement revealed that total skull length (method error: 0.047, PC1: - 0.22) of $m \operatorname{Igf1^{+/+}}$ mice was significantly longer than WT mice at 9 weeks of age. (e) For the viscerocranium section, palatal length (method error: 0.049, PC1: - 0.23) of $m I g f 1^{+++}$mice was significantly longer than WT mice at 6 and 9 weeks of age. (f) $m I g f 1^{+/+}$mice had significantly longer mandibular ramus (method error: 0.096, PC1: -0.22) at 6 weeks of age when compared to WT mice. (g) Representative $\mu$ CT images superimposed to show the difference in the mandibular plane angle of WT (red line) and $m I g f 1^{+/+}$(yellow line) mice at 6 weeks of age. (h) $m I g f 1^{+/+}$mice had a larger mandibular plane angle (method error: 0.376, PC1: -0.08 ) at 3 weeks of age but remained unchanged throughout the study, however WT mice started with smaller mandibular plane angle at 3 weeks but increased significantly at the 6-week and 12-week timepoints when compared to the 3-week timepoint. (d,e,f,h) Data presented are mean \pm SEM. ${ }^{*} p<0.05$ between genotypes. $p<0.05$ : ${ }^{\dagger}$ vs. 3 week, ${ }^{\#}$ vs. 6 week and ${ }^{\theta}$ vs. 9 week within group (Bonferroni's post-hoc analysis). 


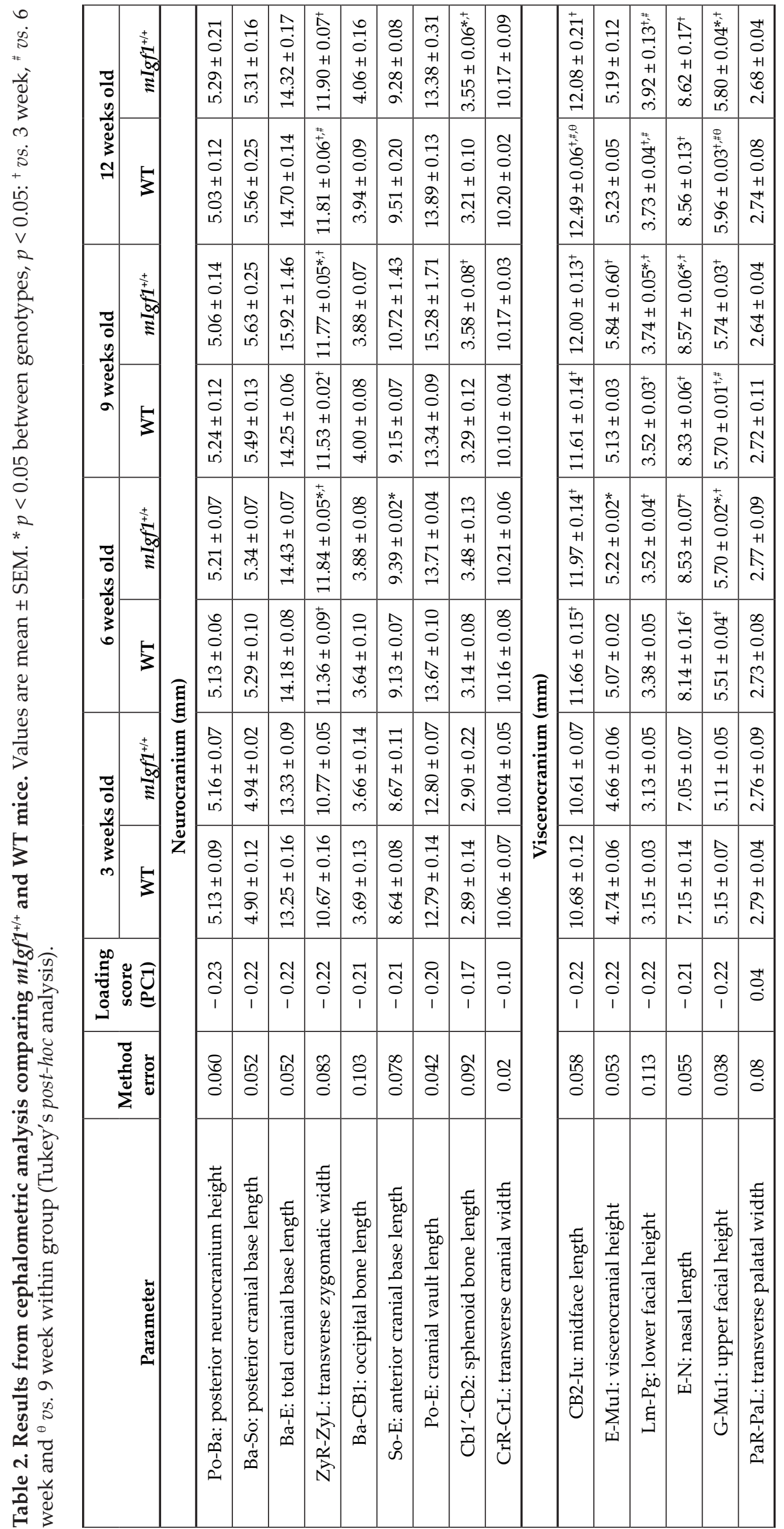




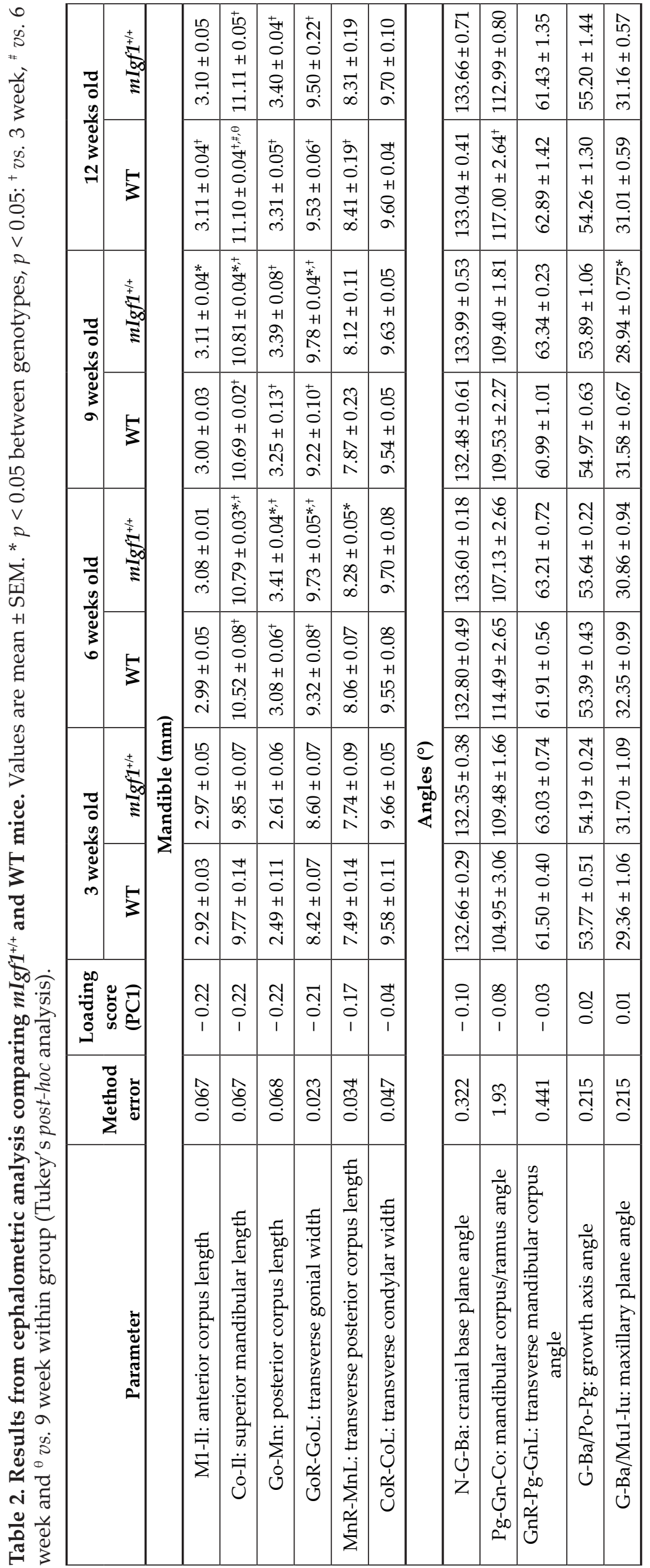


effect when comparing timepoints in posterior cranial base length, total cranial base length and occipital bone length, there were no appreciable differences in other neurocranium measurements (Table 2).

As indicated by the PCA graph, viscerocranial measures of palatal length, midface length, nasal length and upper facial height measurements showed differences between the 3-week timepoint and all other timepoints in both strains (Table 2). With the highest PC1 loading score of -0.23 among viscerocranium (facial skeleton) measurements, the palatal length in $m I g f 1^{+/+}$mice was significantly longer at the 6- and 9-week timepoints when compared to WT mice (Fig. 3e). While $m I g f 1^{+++}$mice retained constant palatal lengths from 6 to 12 weeks of age, WT mice were able to catch up in palatal length as indicated by significant differences between the 12week timepoint and the 6- and 9-week timepoints and was not different when compared to $m I g f 1^{+/+}$mice at the 12-week timepoint. A similar growth trend occurred in the midface as well as upper and lower facial height measurements, where $m \operatorname{Igf1} 1^{+/+}$mice maintained a constant length from the 6- to 12- week timepoints, but WT mice continued to grow, as shown by significant differences between the 12-week and the 6- and/or 9-week timepoints (Table 2). Although midface length had the second highest PC1 loading score, there were no significant differences between strains throughout the study. $m I g f 1^{+/+}$mice also had longer viscerocranial height, lower and upper facial height and nasal length, when compared to WT mice 6, 9 and/or 12 weeks old. Finally, the viscerocranial measurement of transverse palatal width showed no observable differences throughout the study in either strain. Taken together, these measurements indicated accelerated craniofacial growth in $m I g f 1^{+++}$mice.

The mandibular measurements also contributed to differences between genotypes and ages. The ramus height was a representative mandibular measurement with a PC1 loading score of -0.22 and was significantly greater in $\mathrm{mIgf1}^{+/+}$mice than in WT mice at 6 weeks of age (Fig. 3f). Similar to the other craniofacial structures, growth in $m I g f 1^{+++}$mice preceded that in WT mice, leading to larger values for a
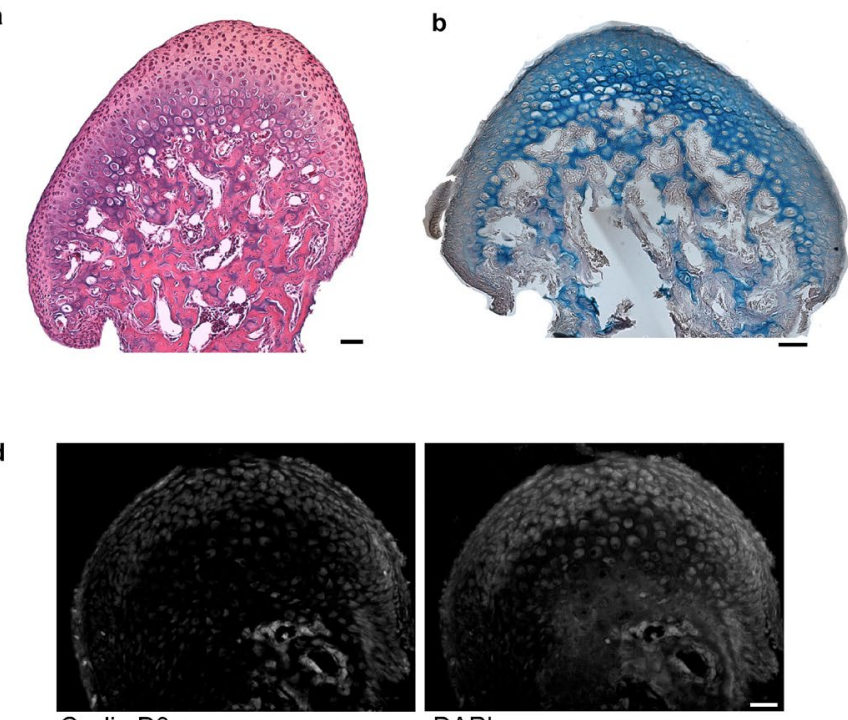

Cyclin D3

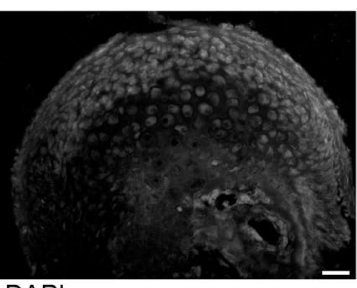

DAPI

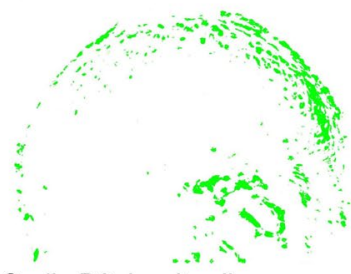

Cyclin D3 density slice

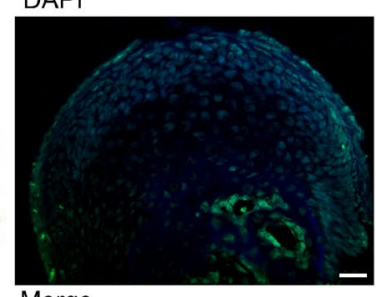

Merge

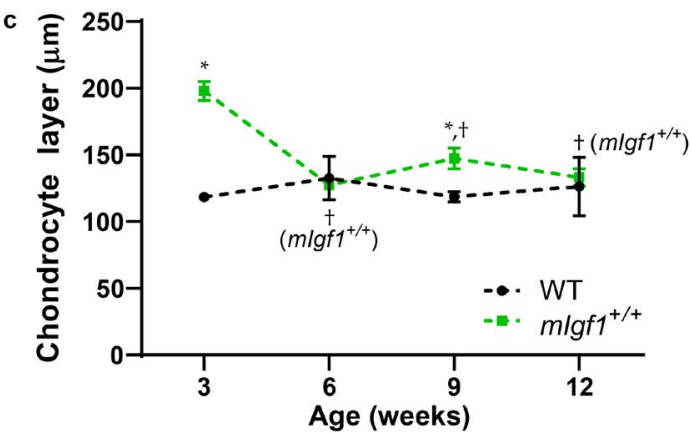

e

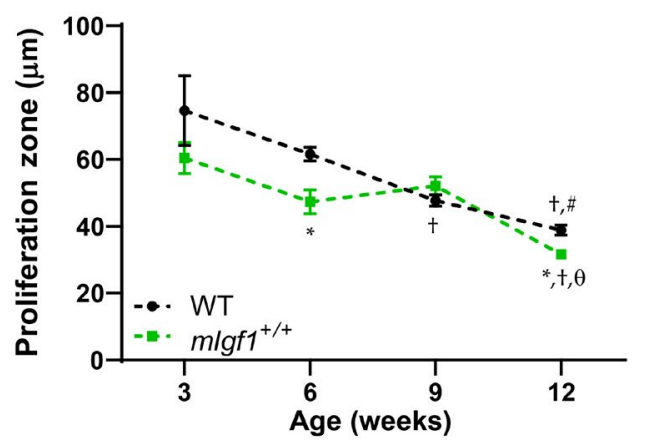

Fig. 4. Accelerated endochondral growth in $m I g f 1^{+/+}$condyles. Representative images from (a) haematoxylin and eosin- and (b) AB-PAS-stained 3-week-old WT mandibular condyles showing the cartilage region spanning from the fibrous layer to the endochondral ossification region. Scale bar: $100 \mu \mathrm{m}$. (c) Measurements of growth plate from AB-PAS mandibular condyles showed significant differences between WT and $m I g f 1^{+++}$ condyles at the 3- and 9-week timepoints. (d) Similar representative images of a 3-week-old WT mandibular condyle stained with cyclin D3 (green) and DAPI (blue), along with the merged image. Scale bar: $100 \mu \mathrm{m}$. Measurements of proliferating zone was performed by utilising the density slice of cyclin D3 images. (e) The proliferation zone of $m I g f 1^{+++}$condyles were smaller than WT animals at the 6- and 12-week timepoints. (c,e) Data presented are mean \pm SEM. ${ }^{*} p<0.05$ between genotypes, $p<0.05:{ }^{\dagger} v s .3$ weeks and ${ }^{\sharp}$ vs. 6 weeks within group (Bonferroni's post-hoc analysis). 
superior mandibular length, posterior corpus length, transverse gonial width and transverse posterior corpus length in 6- and/or 9-week-old $m I g f 1^{+/+}$mice, a difference which disappeared by 12 weeks of age (Table 2). Only the transverse condylar width showed no differences between strains or across age (Table 2). Thus, for all craniofacial regions, increased muscle IGF-I led to faster growth after weaning.

Angular measurements were performed to evaluate differences in growth vectors. Specifically, with observations that the ramus height of the mandible was significantly changed (Fig. 3f), the mandibular plane angle of WT and $m I g f 1^{+/+}$mice was measured (Fig. 3g). There was a larger mandibular plane angle in $m I g f 1^{+/+}$mice compared to WT mice at 3 weeks of age, but significantly smaller at 6 weeks of age (Fig. 3h). A decrease in this angle occurred at 9 weeks of age in the WT mice. This suggested that the structures contributing to the mandibular plane angle changed at different ages during post-weaning growth, with elongation of the skull length causing a reduced angle and increases in dimensions of height increasing the angle. There were no appreciable differences in other angular measurements including the cranial base plane angle, transverse mandibular corpus angle, growth axis angle and maxillary plane angle (Table 2).

\section{Muscle-specific IGF-I contributed to the endochondral growth of mandibular condyles} Due to major changes observed in the mandibular region from $\mu \mathrm{CT}$ measurements, the mandibular condylar cartilage of $m I g f 1^{++}$and WT mice was assessed, as this region plays an important role in postnatal craniofacial growth (Silbermann and Frommer, 1972). Haematoxylin and eosin (Fig. 4a) as well as AB-PAS (Fig. 4b) staining of mandibular condyles from $m I g f 1^{+/+}$and WT mice was performed to visualise the fibrous, proliferative, chondroblastic and hypertrophic layers on the mandibular condylar growth plate. Measurements of the chondrocyte layer spanning the fibrous to endochondral ossification region revealed that the chondrocyte regions were $40 \%$ thicker in $m I g f 1^{+/+}$mice at 3 weeks of age
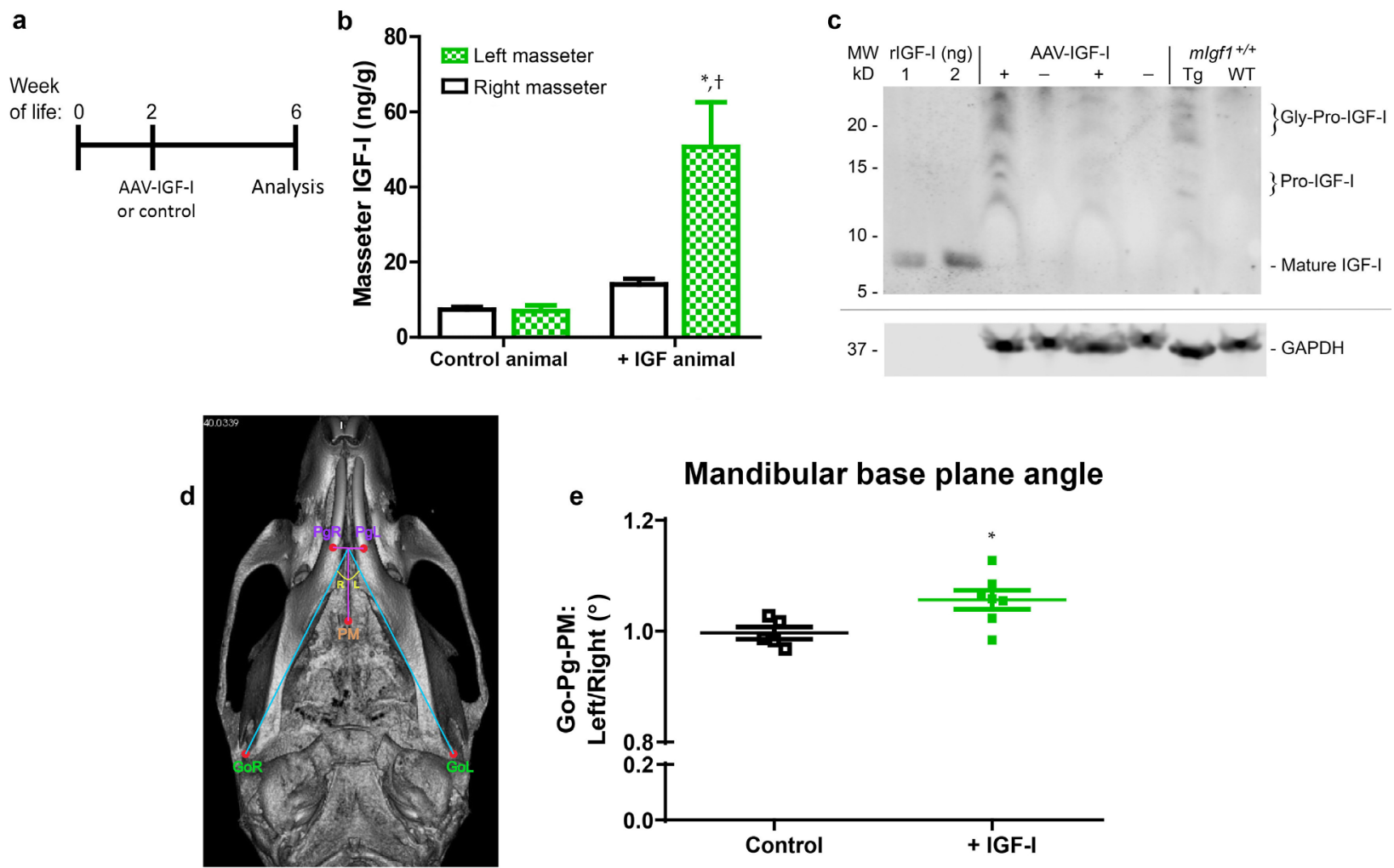

Fig. 5. Overexpression of IGF-I in the masseter altered the mandibular structure. (a) 2-week-old male and female WT mice received AAV-IGF-I $(n=7)$ injection in the left masseter and then were sacrificed 1 month later, along with non-injected control mice $(n=5)$. (b) There were significantly higher IGF-I levels in the AAV-IGF-I-injected masseter (left) when compared to contralateral PBS-injected masseter (right). Data presented are mean \pm SEM. ${ }^{*} p<0.05$ comparing control and + IGF-I animal, ${ }^{\dagger} p<0.05$ for AAV-IGFI-injected vs. PBS-injected masseter in the same animal. (c) Immunoblotting for IGF-I shows that the AAVIGF-I-injected muscles and muscles from the $m I g f 1^{+++}$mice produced the same IGF-I forms, which were predominantly pro- and glycosylated pro-IGF-I. rIGF-I: recombinant mouse IGF-I. GAPDH immunoblot served as an indicator of equal loading. (d) 2D projection of a skull image showing the mandibular base plane angle defined by comparing angles between Go right-PM and Go left-PM. (e) Overexpression of IGF-I in the masseter significantly increased the mandibular base plane angle when compared to control animals. Individual values plotted for all animals. ${ }^{*} p<0.05$ comparing control and + IGF-I animals. 
compared to WT mice (Fig. 4c). Thickness of the growth plate decreased after weaning in $m I g f 1^{+/+}$ mice, suggesting stabilisation of skeletal growth similar to that observed in the cephalometric analysis. Importantly, $m I g f 1^{+/+}$mice had a thicker chondrocyte layer at 9 weeks of age when compared to WT mice. To delve into the nature of the changes in growth plate thickness, cyclin D3 immunostaining was performed to detect proliferating chondrocytes (Fig. $4 d)$. In both strains, there was an age-dependent decrease in the proliferating zone, as the condyle matured, with a slightly smaller proliferating zone in $m I g f 1^{+/+}$mice 6 and 12 weeks old. While not directly measured, this suggested that the hypertrophic zone was much thicker in the 3 -week-old $m I g f 1^{+++}$mice. Together, these data supported enhanced maturation of the condyle in $m I g f 1^{+/+}$mice.

Virus-mediated overexpression of IGF-I in the masseter altered the mandibular structure

Virus-mediated IGF-I overexpression was performed (AAV-IGF-I) in WT mice to limit the effect of IGF-I actions on the masseter and mandibular skeleton. A cohort of mice received AAV-IGF-I injections (+ IGF-I) into the left masseter at 2-weeks of age while the right masseter served as an internal control, with an equal volume of PBS injected. Another cohort of mice was used as non-injected control. In both groups, the experiments were terminated 1-month post-injection (Fig. 5a). The overexpression of IGF-I was validated in the masseter, evidenced by a significant increase in IGF-I protein levels, specifically in the left masseter of the + IGF-I group when compared to the PBSinjected right masseter and also the left masseter of the non-injected control group (Fig. 5b). In addition, the levels and forms of IGF-I produced by AAV injection into WT animals were compared to those in the muscles from $m I g f 1^{+/+}$mice. Both glycosylated and non-glycosylated pro-IGF-I were detected but not mature IGF-I in + IGF-I and $m I g f 1^{+/+}$muscles (Fig. 5c). $\mu$ CT imaging was performed with the focus on measuring the mandibular base plane angle to determine the unilateral alteration of mandibles from an inferior view (Fig. 5d). Indeed, the + IGF-I group had significantly larger alterations after normalising the AAV-IGF-I-injected left to the PBS-injected right side of the mandibular base plane angle (Fig. 5e). Data suggested that masseter IGF-I altered mandibular structure in a lateral angle, as other parameters such as inferior mandibular length, ramus height and ramus angle were not different compared to the PBS-injected masseter and the non-injected control group (Table 3). This experiment revealed that local postnatal IGF-I administration was a potent method for craniofacial bone alterations. Taken together, local muscle IGF-I is important for post-natal craniofacial bone growth, specifically in the mandibular plane of the skull.

\section{Response of bone growth mediated by muscle IGF-I overexpression was absent in MKR mice}

To determine if the actions of muscle IGF-I on bone growth was direct (biochemical) or indirect (mechanical), the viral-mediated overexpression (AAV-IGF-I) experiment was extended to include MKR mice. These mice harbour a dominant negative IGF-IR transgene in the muscle that results in smaller muscle mass and function that cannot be rescued by IGF-I or GH (Barton et al., 2010; Fernández et al., 2002; Kim et al., 2005). Thus, the hypothesis that muscle mass, which provides a major mechanical stimulus to the bone, is not the sole determinant of bone growth was tested. Viral expression caused significant increases in IGF-I protein levels in muscles from both WT and MKR mice (Fig. 6a). Measurements of inferior mandibular length indicated that there was augmented growth from IGF-I overexpression at 6 weeks of age in WT mice, but this response
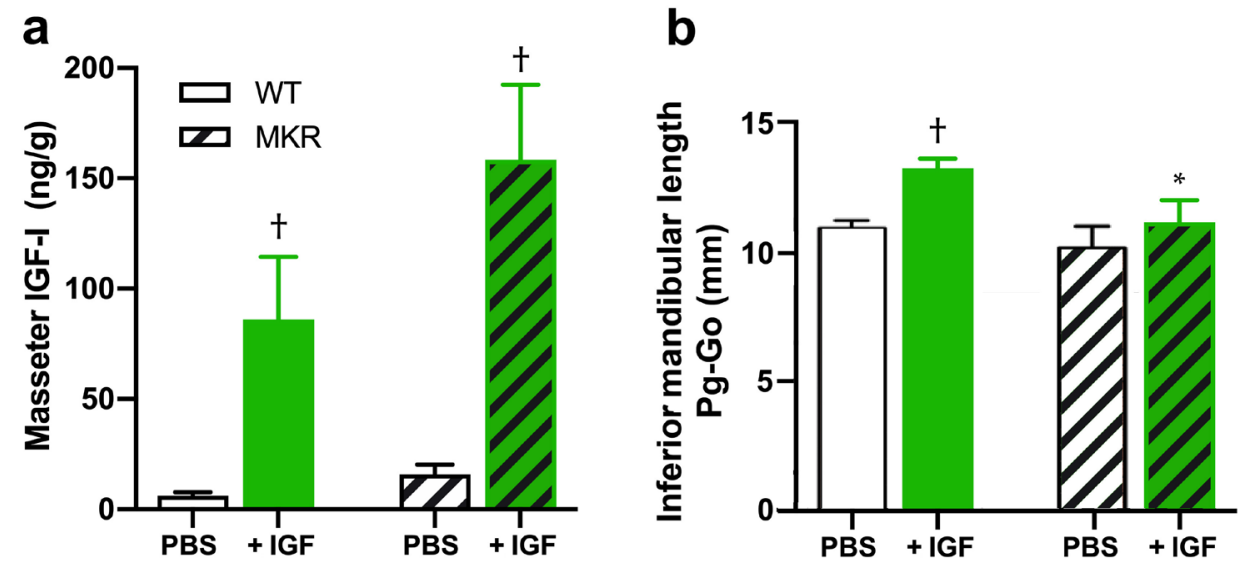

Fig. 6. Overexpression of IGF-I in the masseter augmented mandibular growth in WT mice but not in MKR mice. (a) There were significantly higher IGF-I levels in AAV-injected masseters in both WT and MKR mice. (b) Unilateral AAV-IGF-I injection into the masseter augmented the inferior mandibular length in WT mice at 6 weeks of age, but this effect was absent in MKR mice. Data presented are mean \pm SEM. ${ }^{*} p<0.05$ comparing WT and MKR mice, ${ }^{+} p<0.05$ for AAV-IGF-I-injected vs. PBS-injected masseter in the same animal. 
Table 3. Results from mandibular and angular measurements showed no significant difference when comparing left (AAV-IGF-I-injected) and right (PBS-injected) sides. Values are mean \pm SEM.

\begin{tabular}{|l|c|c|c|c|c|c|}
\hline \multirow{2}{*}{ Parameter: mandible (mm) } & \multicolumn{3}{|c|}{ Control } & \multicolumn{3}{c|}{ + IGF-I } \\
\cline { 2 - 7 } & Right & Left & Left/Right & Right & Left & Left/Right \\
\hline Pg-Go: inferior mandibular length & $13.84 \pm 0.20$ & $13.82 \pm 0.27$ & $1.00 \pm 0.02$ & $13.66 \pm 0.47$ & $13.79 \pm 0.24$ & $1.02 \pm 0.04$ \\
\hline Co-Gn: ramus height & $5.50 \pm 0.18$ & $5.54 \pm 0.20$ & $1.01 \pm 0.05$ & $5.10 \pm 0.16$ & $5.30 \pm 0.17$ & $1.04 \pm 0.04$ \\
\hline Parameter: angle ( $\left.{ }^{\circ}\right)$ & \multicolumn{3}{|c|}{ Control } & \multicolumn{3}{c|}{ + IGF-I } \\
\hline Pg-Go-Co-Gn: ramus angle & \multicolumn{3}{|c|}{$55.22 \pm 1.25$} & \multicolumn{3}{c|}{52.1 .03} \\
\hline
\end{tabular}

was not present in MKR mice (Fig. 6b). Indeed, MKR mice retained a smaller mandible with IGF-I overexpression as indicated by the significant difference between WT and MKR mice on the AAVIGF-I-injected side. These findings implicated that the actions of muscle IGF-I on mandibular bone growth occurred in an indirect (mechanical) manner.

\section{Discussion}

IGF-I plays a major role in postnatal muscle and bone development (Barton and Crowder, 2010; Bikle et al., 2015; Lupu et al., 2001; Powell-Braxton et al., 1993; Vassilakos et al., 2019). Results highlighted the role of muscle IGF-I in regulating craniofacial bone development by augmenting endochondral bone formation. This alteration was specific to the facial and mandibular region of the skull, suggesting a potential therapeutic intervention for children with GHD in resolving delayed growth isolated to the facial and mandibular region.

The accelerated craniofacial bone growth in the transgenic mice with muscle IGF-I overexpression $\left(m I g f 1^{+/+}\right)$can be attributed to the mechanisms associated with mechanical force and/or biochemical secretion in a paracrine fashion (Hamrick et al., 2010). The hypertrophic response of muscle beds due to IGF-I has the potential to provide the benefits of mechanical loading to the bone in order to induce bone formation. Indeed, muscular contraction facilitates mechanical stimulation of the bone (Brotto and Bonewald, 2015); however, the emerging role of myokines in regulating bone formation remains to be fully elucidated (Hamrick, 2011).

$m I g 1^{+/+}$mice showed significant acceleration of long bone (Fig. 2) and craniofacial (Fig. 3, Table 2) skeletal development at 6 weeks of age. Accelerated craniofacial growth was isolated to the facial and mandibular region, excluding the calvarial bone. Data were in alignment with studies that utilised systemic GH or IGF-I as a therapeutic intervention in both human and animal models suffering from GHD (Backeljauw et al., 2013; Chernausek et al., 2007; Choi et al., 2017; Funatsu et al., 2006; Lewinson et al., 1994; Singleton et al., 2006).

Since orthodontic treatment is a common need among diseases with craniofacial abnormalities (Barton and Crowder, 2010; Hwang and Cha, 2004;
Wójcik and Beń-Skowronek, 2020), the benefits of muscle IGF-I in the mandibular region were further studied. In $m I g f 1^{+/+}$mice, the mandibular plane angle was smaller during the active growth in the equivalent adolescent phase when compared to WT animals (Fig. 3h), suggesting a more precise growth vector due to IGF-I overexpression. To identify if this growth vector was attributed to the horizontal or vertical shift in the mandible, virus-mediated IGF-I delivery was performed into the masseter. From the inferior view of the mandibular base plane angle, the injected side grew in width when compared to the non-injected side (Fig. 5d). However, there was no change in ramus height comparing injected and non-injected sides (Table 3). Thus, local IGF-I from the masseter had a role in expanding the mandibular angle in a lateral manner. Although there was a vertical effect in $m I g f 1^{+++}$mice (Fig. 3f), this was attributed to the actions of IGF-I from multiple craniofacial muscle groups. Despite the fact that masseter thickness positively correlates to mandibular ramus height in a human model (Kubota et al., 1998), rodents rely on the posterior temporal muscle and anterior digastric muscle to alter the mandibular ramus (Cruz et al., 2009; Lifshitz, 1976). Thus, data with IGF-I overexpression recapitulated the human model where $m I g f 1^{+/+}$mice captured the vertical effect due to IGF-I action from muscle groups, while the AAV-IGF-I experiment captured the horizontal effect indicating a specific role of the masseter. Because the masseter inserts along the lateral area of the mandibular ramus, this posits a potential for utilising it to deliver IGF-I in correcting facial asymmetry among GHD children, where mandibular lateral displacement is evident (Pan et al., 2013; Pirttiniemi et al., 2009).

Proposed models suggest that the muscle provide a local source of growth factors for the bone (Bikle et al., 2015; Hamrick et al., 2010; Hamrick, 2011). Indeed, muscle secretes IGF-I as a myokine and this source has an endocrine and paracrine role in overall body growth (Vassilakos et al., 2019). The speculation of muscle-bone interaction by IGF-I is determined by observations of IGF-IR localised at the periosteum by the muscle surface (Hamrick et al., 2010). However, whether bone relies on paracrine IGF-I from the neighbouring muscle remains an unanswered question. MKR mice were utilised in determining if bone growth modulated by muscle 
IGF-I occurred directly, as a ligand (biochemically), or indirectly, through mechanical stimulus provided by IGF-I-mediated muscle hypertrophy. MKR mice retain a smaller muscle mass and are unable to be rescued by IGF-I or GH (Barton et al., 2010; Fernández et al., 2002; Kim et al., 2005), thus AAV-IGF-I injection did not alter the muscle cross sectional area in the present study (data not shown). This allowed for determining the effect of muscle IGF-I in the absence of mechanical stimulation to the bone. While there was an augmented sagittal growth in WT animals at 6 weeks of age, this growth is non-existent in MKR mice. This may reflect that sagittal growth is more affected by muscle strength and mechanical loading than the biochemical effect of IGF-I.

There is no doubt that the skeletal muscle is a major source of mechanical loading for bone anabolism. In the mandibular condylar cartilage, $5 \mathrm{~d}$ of loading increase mandibular and condylar length, along with cartilage expansion (Kaul et al., 2016). This prompted the interrogation of the mandibular condylar growth plate at the cellular level. The increased chondrocyte layer (Fig. $4 \mathrm{~g}$ ) in $\mathrm{mIgf1}^{+/+}$mice provided evidence that chondrocyte proliferation relied on mechanical cues from IGF-I-mediated muscle hypertrophy. Alternatively, mechanical loading due to earlier exploration of hard food by $\mathrm{IIgf1}^{+++}$mice pre-weaning could have occurred, but this was not directly addressed. Although there was no visible expansion of the proliferation zone in $m I g f 1^{+++}$mice (Fig. 4h), it is possible that the hypertrophic cell layer was where the expansion occurred during the time of measurement. Data suggested that the effects of muscle hypertrophy from IGF-I overexpression likely caused a mechanical-load-mediated expansion in the mandibular growth plate.

With the above interpretation in place, it was intriguing that $m I g f 1^{+/+}$mice displayed accelerated bone growth, but that the WT mice caught up by 12 weeks of age, suggesting that the continued presence of high levels of muscle IGF-I did not create a continued anabolic drive to the craniofacial skeleton and an acromegaly phenotype. On one hand, the absence of acromegaly suggested that there was a limited window where high levels of muscle IGF-I may alter craniofacial growth. In particular, the actions accelerated the already rapid growth associated with early post-natal development. Another aspect to consider is that all striated muscles are assumed to have high levels of IGF-I in the transgenic mouse in contrast to the mice where AAV delivery was performed only in the masticatory region. Hence, the transgenic craniofacial skeleton is potentially "bathed" in IGF-I secreted from all muscles, and/or subjected to mechanical forces along multiple vectors. This, combined with the deceleration of skeletal growth, suggested it may be difficult to discern continued increases in the skeletal proportions. A similar observation occurs in murine muscles when viral IGF-I is administered at older ages. Injections of AAV-IGF-I at 1-3 weeks of age results in $\sim 15 \%$ increases in muscle mass; viral injections at 5 months of age results in $\sim 5 \%$ increases in muscle mass (Barton, 2006); viral injections at 18 months of age result in no change in muscle mass, but do preserve the existing muscle mass (BartonDavis et al., 1998). Whether the same phenomenon occurs in craniofacial skeletal growth under similar experimental conditions has not been addressed.

Given the fact that increased IGF-I levels in transgenic animals caused accelerated growth, the findings in the mice subjected to viral delivery of Igf1a were interpreted as accelerated growth on the treated side, rather than constricted growth on the side contralateral to AAV injections (Fig. 5e). As measurements were terminal and only taken at one timepoint, it is not clear which adaptation occurred. Future studies could monitor mice over time with repeated measures of the craniofacial skeleton to determine which was the case. It will be important to address this aspect in light of any potential clinical applications of a muscle-directed strategy to correct facial asymmetries.

In the present study, the focus was restricted to the major class and isoform of IGF-I in skeletal muscle, Igf1a, in order to determine the impact of what is normally found in homeostatic muscle. However, remodelling muscle can produce other forms, including $I g f 1 b / c$ isoforms, which cannot be glycosylated, may have less retention in the matrix and may have a greater ability to diffuse to the bone. Further, boosting mature IGF-I may also be more effective in diffusion. However, given it has a short half-life in the absence of IGF binding protein stabilisation, the free mature ligand could degrade prior to arriving at the bone or the IGF-IGF binding protein complex would remain in the muscle. Because no effects of increased Igfla expression were observed on mandibular growth in MKR mice, the effect of additional isoforms was not explored.

The study revealed the indirect effect of muscle IGF-I on bone growth. Depletion of systemic GH and IGF-I affects the craniofacial skeleton (McAlarney et al., 2001; Omar Ramirez-Yañez et al., 2005; Singleton et al., 2006). Thus, strategies such as GH and IGF-I replacement therapy have been targeted for many diseases related to GH and IGF deficiencies (Backeljauw et al., 2013; Grimberg et al., 2016). While systemic treatments can improve craniofacial bone development (Funatsu et al., 2006; Singleton et al., 2006), evidence of soft tissue growth, such as muscles, in the craniofacial region have also been reported (Backeljauw et al., 2013; Cohen et al., 2014). Indeed, local administration of GH and IGF-I promotes chondrocyte growth (Ok et al., 2020) and endochondral bone formation (Wang et al., 2019), indicating the necessity of GH/IGF-I axis in regulating craniofacial bones. The present study recapitulated the effect of IGF-I in targeting endochondral expansion and further craniofacial 
bone growth. Specifically, local IGF-I administration into the muscle had the capacity to alter bone growth. This posits a major benefit in targeting specific bone growth either vertically or horizontally for correcting any disproportionate growth in the craniofacial bone that occurs in children with GHD, as children with GHD tend to have smaller mandible and facial proportions when compared to the calvarial region (Wójcik and Beń-Skowronek, 2020). Although the present study did not address if this effect could be extended to adult animals, the influence of IGF-I on an adult mandibular condylar growth plate may be akin to the present study given that secondary cartilage contains undifferentiated mesenchyme differing to the appendicular primary skeletal cartilage. Overall, IGF-I is highly potent in regulating secondary cartilage but the role of muscle IGF-I in regulating craniofacial bone growth is attributed to its direct effects on muscle size, which then indirectly modulates bone growth.

\section{Conclusions}

Local muscle IGF-I could alter craniofacial bone growth predominantly through mechanical actions. This enhanced the endochondral bone growth from increased thickness of the mandibular condylar cartilage, resulting in horizontal and vertical alteration of the mandible. Overall growth of the skull was also evident with transgenic overexpression of muscle IGF-I, but more significant growth occurred at the facial and mandibular regions. Similar growth trends occurred in long-bone growth, where the humerus length was longer from 6 weeks of age throughout the study. Findings in the mouse model using transgenic and virus-mediated IGF-I overexpression strategy mimicked findings from long-term IGF-I therapy for GHD and IGFD children, where growth in the facial soft tissue, such as the muscle, is accompanied by facial bone growth improving both linear and angular measurements. Orthodontic treatment is the accepted therapy for facial asymmetry in GHD children, however considerations of mechanical loading and IGF-I treatment into the muscle may pose a less invasive alternative. Summarising, the study provided evidence that local IGF-I administration into the muscle may be an effective therapeutic target for diseases associated with craniofacial abnormalities through its hypertrophic actions on muscle.

\section{Acknowledgements}

This study was supported by the University of Pennsylvania Research Foundation and the Joseph and Josephine Rabinowitz Award for Excellence in Research to ERB.

\section{References}

Backeljauw PF, Kuntze J, Frane J, Calikoglu AS, Chernausek SD (2013) Adult and near-adult height in patients with severe insulin-like growth factor-I deficiency after long-term therapy with recombinant human insulin-like growth factor-I. Horm Res Paediatr 80: 47-56.

Baker J, Liu JP, Robertson EJ, Efstratiadis A (1993) Role of insulin-like growth factors in embryonic and postnatal growth. Cell 75: 73-82.

Balanta-Melo J, Torres-Quintana MA, Bemmann M, Vega C, González C, Kupczik K, Toro-Ibacache $\mathrm{V}$, Buvinic S (2018) Masseter muscle atrophy impairs bone quality of the mandibular condyle but not the alveolar process early after induction. J Oral Rehabil 46: 233-241.

Barton ER (2006) Viral expression of insulinlike growth factor-I isoforms promotes different responses in skeletal muscle. J Appl Physiol 100: 1778-1784.

Barton ER, Crowder C (2010) Growth factor targets for orthodontic treatments. Semin Orthod 16: 128-134.

Barton ER, Demeo J, Lei H (2010) The insulinlike growth factor (IGF)-I E-peptides are required for isoform-specific gene expression and muscle hypertrophy after local IGF-I production. J Appl Physiol 108: 1069-1076.

Barton ER, Park S, James JK, Makarewich CA, Philippou A, Eletto D, Lei H, Brisson B, Ostrovsky O, Li Z, Argon Y (2012) Deletion of muscle GRP94 impairs both muscle and body growth by inhibiting local IGF production. FASEB J 26: 3691-3702.

Barton-Davis ER, Shoturma DI, Musaro A, Rosenthal N, Sweeney HL (1998) Viral mediated expression of insulin-like growth factor i blocks the aging-related loss of skeletal muscle function. Proc Natl Acad Sci U S A 95: 15603-15607.

Batey L, Moon JE, Yu Y, Wu B, Hirschhorn JN, Shen Y, Dauber A (2014) A novel deletion of Igf1 in a patient with idiopathic short stature provides insight into Igf1 haploinsufficiency. J Clin Endocrinol Metab 99: E153-159.

Bikle DD, Tahimic C, Chang W, Wang Y, Philippou A, Barton ER (2015) Role of IGF-I signaling in muscle bone interactions. Bone 80: 79-88.

Brotto M, Bonewald L (2015) Bone and muscle: Interactions beyond mechanical. Bone 80: 109-114.

Chernausek SD, Backeljauw PF, Frane J, Kuntze J, Underwood LE (2007) Long-term treatment with recombinant insulin-like growth factor (IGF)-I in children with severe IGF-I deficiency due to growth hormone insensitivity. J Clin Endocrinol Metab 92: 902-910.

Choi SH, Fan D, Hwang MS, Lee HK, Hwang CJ (2017) Effect of growth hormone treatment on craniofacial growth in children: idiopathic short stature versus growth hormone deficiency. J Formos Med Assoc 116: 313-321. 
Cohen J, Blethen S, Kuntze J, Smith SL, Lomax KG, Mathew PM (2014) Managing the child with severe primary insulin-like growth factor-1 deficiency (IGFD): IGFD diagnosis and management. Drugs R D 14: 25-29.

Conith AJ, Lam DT, Albertson RC (2019) Muscleinduced loading as an important source of variation in craniofacial skeletal shape. Genesis 57: e23263. DOI: $10.1002 / d v g .23263$.

Cruz DZ, Rodrigues L, Luz JGDC (2009) Effects of detachment and repositioning of the medial pterygoid muscle on the growth of the maxilla and mandible of young rats. Acta Cir Bras 24: 93-97.

Dauber A, Rosenfeld RG, Hirschhorn JN (2014) Genetic evaluation of short stature. J Clin Endocrinol Metab 99: 3080-3092.

Durzynska J, Philippou A, Brisson BK, NguyenMcCarty M, Barton ER (2013a) The pro-forms of insulin-like growth factor I (IGF-I) are predominant in skeletal muscle and alter IGF-I receptor activation. Endocrinology 154: 1215-1224.

Durzynska J, Wardzinski A, Koczorowska M, Gozdzicka-Jozefiak A, Barton ER (2013b) Human eb peptide: not just a by-product of pre-pro-IGF1b processing? Horm Metab Res 45: 415-422.

Fernández AM, Kim JK, Yakar S, Dupont J, Hernandez-Sanchez C, Castle AL, Filmore J, Shulman GI, Le Roith D (2001) Functional inactivation of the IGF-I and insulin receptors in skeletal muscle causes type 2 diabetes. Genes Dev 15: 1926-1934.

Fernández AM, Dupont J, Farrar RP, LeeS, Stannard B, Le Roith D (2002) Muscle-specific inactivation of the IGF-I receptor induces compensatory hyperplasia in skeletal muscle. J Clin Invest 109: 347-355.

Fuentes MA, Opperman LA, Bellinger LL, Carlson DS, Hinton RJ (2002) Regulation of cell proliferation in rat mandibular condylar cartilage in explant culture by insulin-like growth factor-1 and fibroblast growth factor-2. Arch Oral Biol 47: 643-654.

Funatsu M, Sato K, Mitani H (2006) Effects of growth hormone on craniofacial growth: duration of replacement therapy. Angle Orthod 76: 970-977.

Govoni KE, Wergedal JE, Florin L, Angel P, Baylink DJ, Mohan S (2007) Conditional deletion of insulin-like growth factor-i in collagen type 1alpha2expressing cells results in postnatal lethality and a dramatic reduction in bone accretion. Endocrinology 148: 5706-5715.

Grimberg A, DiVall SA, Polychronakos C, Allen DB, Cohen LE, Quintos JB, Rossi WC, Feudtner C, Murad MH (2016) Guidelines for growth hormone and insulin-like growth factor-I treatment in children and adolescents: growth hormone deficiency, idiopathic short stature, and primary insulin-like growth factor-I deficiency. Horm Res Paediatr 86: 361-397.

Gross TS, Srinivasan S, Liu CC, Clemens TL, Bain SD (2002) Noninvasive loading of the murine tibia: an in vivo model for the study of mechanotransduction. J Bone Miner Res 17: 493-501.
Hamrick MW (2011) A role for myokines in muscle-bone interactions. Exerc Sport Sci Rev 39: 43-47.

Hamrick MW, McNeil PL, Patterson SL (2010) Role of muscle-derived growth factors in bone formation. J Musculoskelet Neuronal Interact 10: 64-70.

Hede MS, Salimova E, Piszczek A, Perlas E, Winn N, Nastasi T, Rosenthal N (2012) E-peptides control bioavailability of igf-1. PLoS One 7: e51152. DOI: 10.1371/journal.pone.0051152.

Herrmann M, Engelke K, Ebert R, Müller-Deubert S, Rudert M, Ziouti F, Jundt F, Felsenberg D, Jakob F (2020) Interactions between muscle and bone-where physics meets biology. Biomolecules 10: 432. DOI: 10.3390/biom10030432.

Hwang CJ, Cha JY (2004) Orthodontic treatment with growth hormone therapy in a girl of short stature. Am J Orthod Dentofacial Orthop 126: 118126.

Kandalla PK, Goldspink G, Butler-Browne G, Mouly V (2011) Mechano growth factor e peptide (mgf-e), derived from an isoform of IGF-1, activates human muscle progenitor cells and induces an increase in their fusion potential at different ages. Mech Ageing Dev 132: 154-162.

Kaul R, O’Brien MH, Dutra E, Lima A, Utreja A, Yadav S (2016) The effect of altered loading on mandibular condylar cartilage. PLoS One 11: e0160121. DOI: 10.1371/journal.pone.0160121.

Kawashima Y, Fritton JC, Yakar S, Epstein S, Schaffler MB, Jepsen KJ, LeRoith D (2009) Type 2 diabetic mice demonstrate slender long bones with increased fragility secondary to increased osteoclastogenesis. Bone 44: 648-655.

Kesavan C, Wergedal JE, Lau KH, Mohan S (2011) Conditional disruption of IGF-I gene in type 1alpha collagen-expressing cells shows an essential role of IGF-I in skeletal anabolic response to loading. Am J Physiol Endocrinol Metab 301: E1191-1197.

Kim H, Barton E, Muja N, Yakar S, Pennisi P, LeRoith D (2005) Intact insulin and insulin-like growth factor-I receptor signaling is required for growth hormone effects on skeletal muscle growth and function in vivo. Endocrinology 146: 1772-1779.

Kjellberg H, Beiring M, Wikland KA (2000) Craniofacial morphology, dental occlusion, tooth eruption, and dental maturity in boys of short stature with or without growth hormone deficiency. Eur J Oral Sci 108: 359-367.

Klein-Nulend J, Bakker AD, Bacabac RG, Vatsa A, Weinbaum S (2013) Mechanosensation and transduction in osteocytes. Bone 54: 182-190.

Kubota M, Nakano H, Sanjo I, Satoh K, Sanjo T, Kamegai T, Ishikawa F (1998) Maxillofacial morphology and masseter muscle thickness in adults. Eur J Orthod 20: 535-542.

Lean JM, Jagger CJ, Chambers TJ, Chow JW (1995) Increased insulin-like growth factor I mRNA expression in rat osteocytes in response to mechanical stimulation. Am J Physiol 268: E318-327. 
Lee SJ, Lehar A, Meir JU, Koch C, Morgan A, Warren LE, Rydzik R, Youngstrom DW, Chandok H, George J, Gogain J, Michaud M, Stoklasek TA, Liu Y, Germain-Lee EL (2020) Targeting myostatin/ activin A protects against skeletal muscle and bone loss during spaceflight. Proc Natl Acad Sci U S A 117: 23942-23951.

Lewinson D, Bialik GM, Hochberg Z (1994) Differential effects of hypothyroidism on the cartilage and the osteogenic process in the mandibular condyle: recovery by growth hormone and thyroxine. Endocrinology 135: 1504-1510.

Lifshitz J (1976) Comparative anatomic study of mandibular growth in rats after bilateral resections of superficial masseter, posterior temporal, and anterior digastric muscles. J Dent Res 55: 854-858.

Litsas G (2015) Growth hormone and craniofacial tissues. An update. Open Dent J 9: 1-8.

Loening AM, Gambhir SS (2003) AMIDE: a free software tool for multimodality medical image analysis. Mol Imaging 2: 131-137.

Lupu F, Terwilliger JD, Lee K, Segre G V., Efstratiadis A (2001) Roles of growth hormone and insulin-like growth factor 1 in mouse postnatal growth. Dev Biol 229: 141-162.

Marchant C, Anderson P, Schwarz Q, Wiszniak $S$ (2020) Vessel-derived angiocrine IGF1 promotes Meckel's cartilage proliferation to drive jaw growth during embryogenesis. Development 147: dev190488. DOI: 10.1242/dev.190488.

Matic DB, Yazdani A, Wells RG, Lee TY, Gan BS (2007) The effects of masseter muscle paralysis on facial bone growth. J Surg Res 139: 243-252.

McAlarney ME, Rizos M, Rocca EG, Nicolay OF, Efstratiadis S (2001) The quantitative and qualitative analysis of the craniofacial skeleton of mice lacking the IGF-I gene. Clin Orthod Res 4: 206-219.

Morel-Verdebout C, Botteron S, Kiliaridis S (2007) Dentofacial characteristics of growing patients with duchenne muscular dystrophy: a morphological study. Eur J Orthod 29: 500-507.

Musarò A, McCullagh K, Paul A, Houghton L, Dobrowolny G, Molinaro M, Barton ER, L Sweeney H, Rosenthal N (2001) Localized Igf-1 transgene expression sustains hypertrophy and regeneration in senescent skeletal muscle. Nat Genet 27: 195-200.

Ok SM, Kim JH, Kim JS, Jeong E gyo, Park YM, Jeon HM, Heo JY, Ahn YW, Yu SN, Park HR, Kim KH, Ahn SC, Jeong SH (2020) Local injection of growth hormone for temporomandibular joint osteoarthritis. Yonsei Med J 61: 331-340.

Omar Ramirez-Yañez G, Smid JR, Young WG, Waters MJ (2005) Influence of growth hormone on the craniofacial complex of transgenic mice. Eur J Orthod 27: 494-500.

Pan CY, Lan TH, Chou ST, Tseng YC, Chang JZC, Chang HP (2013) Orthodontic treatment for a mandibular prognathic girl of short stature under growth hormone therapy. J Formos Med Assoc 112: 801-806.
Paul AC, Rosenthal N (2002) Different modes of hypertrophy in skeletal muscle fibers. J Cell Biol 156: 751-760.

Pfeffer LA, Brisson BK, Lei H, Barton ER (2009) The insulin-like growth factor (IGF)-I E-peptides modulate cell entry of the mature IGF-I protein. Mol Biol Cell 20: 3810-3817.

Pirttiniemi P, Peltomäki T, Müller L, Luder HU (2009) Abnormal mandibular growth and the condylar cartilage. Eur J Orthod 31: 1-11.

Powell-Braxton L, Hollingshead P, Warburton C, Dowd M, Pitts-Meek S, Dalton D, Gillett N, Stewart TA (1993) IGF-I is required for normal embryonic growth in mice. Genes Dev 7: 2609-2617.

Reijnders CM, Bravenboer N, Tromp AM, Blankenstein MA, Lips P (2007) Effect of mechanical loading on insulin-like growth factor-I gene expression in rat tibia. J Endocrinol 192: 131-140.

Seok H, Kim S-G, Kim M-K, Jang I, Ahn J (2018) Effect of the masseter muscle injection of botulinum toxin $\mathrm{A}$ on the mandibular bone growth of developmental rats. Maxillofac Plast Reconstr Surg 40: 5. DOI: 10.1186/s40902-018-0146-4.

Shi S, Kelly BJ, Wang C, Klingler K, Chan A, Eckert GJ, Trippel SB (2018) Human IGF-I propeptide a promotes articular chondrocyte biosynthesis and employs glycosylation-dependent heparin binding. Biochim Biophys Acta Gen Subj 1862: 567-575.

Silbermann M, Frommer J (1972) The nature of endochondral ossification in the mandibular condyle of the mouse. Anat Rec 172: 659-667.

Singleton DA, Buschang PH, Behrents RG, Hinton RJ (2006) Craniofacial growth in growth hormonedeficient rats after growth hormone supplementation. Am J Orthod Dentofacial Orthop 130: 69-82.

Sjögren K, Liu J-L, Blad K, Skrtic S, Vidal O, Wallenius V, LeRoith D, Törnell J, Isaksson OGP, Jansson J-O, Ohlsson C (1999) Liver-derived insulinlike growth factor I (IGF-I) is the principal source of IGF-I in blood but is not required for postnatal body growth in mice. Proc Natl Acad Sci U S A 96: 70887092.

Suzuki S, Itoh K, Ohyama K (2004) Local administration of IGF-I stimulates the growth of mandibular condyle in mature rats. J Orthod 31: 138143.

Tahimic CG, Wang Y, Bikle DD (2013) Anabolic effects of IGF-1 signaling on the skeleton. Front Endocrinol (Lausanne) 4: 6. DOI: 10.3389/ fendo.2013.00006.

Vandeberg JR, Buschang PH, Hinton RJ (2004) Craniofacial growth in growth hormone-deficient rats. Anat Rec A Discov Mol Cell Evol Biol 278: 561570.

Vassilakos G, Barton ER (2018) Insulin-like growth factor I regulation and its actions in skeletal muscle. Compr Physiol 9: 413-438.

Vassilakos G, Lei H, Yang Y, Puglise J, Matheny M, Durzynska J, Ozery M, Bennett K, Spradlin R, Bonanno H, Park S, Ahima RS, Barton ER (2019) 
Deletion of muscle IGF-I transiently impairs growth and progressively disrupts glucose homeostasis in male mice. FASEB J 33: 181-194.

Wang D, Yang H, Zhang M, Zhang H, Lu L, Zhang J, Wan X, Wang M (2019) Insulin-like growth factor-1 engaged in the mandibular condylar cartilage degeneration induced by experimental unilateral anterior crossbite. Arch Oral Biol 98: 17-25.

Wang Y, Cheng Z, Elalieh HZ, Nakamura E, Nguyen MT, MacKem S, Clemens TL, Bikle DD, Chang W (2011) IGF-1R signaling in chondrocytes modulates growth plate development by interacting with the PTHrP/Ihh pathway. J Bone Miner Res 26: 1437-1446.

Wójcik D, Beń-Skowronek I (2020) Craniofacial morphology in children with growth hormone deficiency and turner syndrome. Diagnostics (Basel) 10: 88. DOI: 10.3390/diagnostics10020088.

Yakar S, Canalis E, Sun H, Mejia W, Kawashima Y, Nasser P, Courtland HW, Williams V, Bouxsein M, Rosen C, Jepsen KJ (2009) Serum IGF-1 determines skeletal strength by regulating subperiosteal expansion and trait interactions. J Bone Miner Res 24: 1481-1492.

Yakar S, Liu J-L, Stannard B, Butler A, Accili D, Sauer B, LeRoith D (1999) Normal growth and development in the absence of hepatic insulin-like growth factor I. Proc Natl Acad Sci U S A 96: 73247329.

Yakar S, Werner H, Rosen CJ (2018) Insulinlike growth factors: actions on the skeleton. J Mol Endocrinol 61: T115-T137.

Yang SY, Goldspink G (2002) Different roles of the IGF-I EC peptide (MGF) and mature IGF-I in myoblast proliferation and differentiation. FEBS Lett 522: 156-160.

\section{Web References}

1. https://github.com/vqv/ggbiplot [01-07-2021]

2. https://cran.r-project.org/package $=$ factoextra [01-07-2021]

\section{Discussion with Reviewer}

Franz Jakob: Is there any chance that virus-based therapy will be translated to humans? What are your suggestions for a therapeutic strategy that uses this local modulation of IGF-I availability to avoid problems in patients affected by GH- or IGFI-deficiency?

Authors: Viral gene therapy approaches to correct genetic disease are currently being evaluated in clinical trials, and in some cases, have been approved for clinical use. These trials have grappled with many of the hurdles associated with viral gene therapy, including dosing limitations, immune responses, efficacy and production. For most, if not all, the target is a genetic disease, with the need for systemic delivery required for a cure. The advantage of a virus-based therapy is the elimination of frequent dosing, as it is expressed from a cell for the lifetime of that cell. For skeletal muscle, a post-mitotic tissue, the expression of any viral transgene could be stable for years.

IGF-I boosts growth of almost all tissues through its activation of IGF-IR. As a mediator of many, but not all, actions of GH, the use of IGF-I can also act as a surrogate for GH deficiency. The delivery of IGF-I by AAV could have distinct advantages over systemic recombinant delivery of IGF-I or GH, particularly for muscle. First, high levels of IGF-I can be achieved locally and, dependent upon the form produced, build up a local reservoir of IGF-I for the muscle and, potentially, adjacent tissues. Second, while a systemic strategy similar to those for genetic diseases could be employed, an alternative is to target the affected tissue, such as a muscle with acute damage or a regional skeletal deformity. From the perspective of the current study, such an approach could be used in lieu of orthognathic surgery to correct receding or asymmetric jaws, although the timing of viral delivery would have to be optimised to be in sync with active skeletal growth. In consideration of patients with GH or IGF-I deficiency, boosting IGF-I specifically in muscle has the advantage of improving strength (and indirectly bone density), glucose handling through increasing bulk muscle for glucose clearance and also IGF-I acting as a metabolic trigger through hybrid receptors.

Editor's note: The Scientific Editor responsible for this paper was Chris Evans. 